\title{
A PROSA POÉTICA DE KATHRYN SIMMONDS: ECOS DICKINSONIANOS NA LITERATURA CONTEMPORÂNEA
}

\author{
Marcela Santos Brigida \\ Mestranda em Letras - Literaturas de Língua Inglesa - pela Universidade do Estado \\ do Rio de Janeiro (UERJ) \\ marcelascastelli@gmail.com
}

\section{RESENHA}

HOPE IS THE THING WITH FEATHERS. The Poet and the Echo, Glasgow: BBC Radio 4, 11 de fevereiro de 2018. Programa de rádio.

Veiculado pela Radio 4 da BBC em fevereiro de 2018, um conto assinado por Kathryn Simmonds inspirado no poema 254 de Emily Dickinson oferece uma atraente instância para análise comparativa. O conto da autora inglesa se insere na proposta do programa The Poet and the Echo de oferecer aos ouvintes uma peça de ficção contemporânea que se desenrole como eco da voz de um poeta escolhido pelo contista. A relação de colaboração entre autores de épocas distintas - os poetas mais recentes, cujas obras foram escolhidas, eram oitocentistas - estabelecida pelo diálogo entre poema e conto convida a uma reflexão acerca dos conceitos de tradição e contemporaneidade na literatura.

The Poet and the Echo é um projeto de celebração da tradição literária, impulsionando o ato criador no escritor ao colocá-lo na posição de leitor, o desafiando a agir. Vemos o enfraquecimento do limiar que distingue os papéis e a elevação do leitor a um polo ativo na relação com o que é escrito. A declamação do poema antes do conto 
acentua a percepção da coabitação das duas obras num ambiente literário que elude a padronização do texto impresso. Neste sentido, Dickinson, uma detratora deste e defensora zelosa dos seus manuscritos e da recitação aparece em seu habitat natural. Em sua biografia da poeta de Amherst, Lyndall Gordon faz referência a este traço afirmando que a familiaridade entre os poemas dickinsonianos e as letras de música de compositores declaradamente inspirados por ela, como o inglês Peter Doherty, se justifica em parte por serem formas que atuam fora das regras padronizadoras da impressão. Dickinson oferece uma obra completa sem as finalizações da impressão e Gordon defende que "isso deixa os seus poemas provisionais, como de fato o eram" (2010, p. 140). Outrossim, uma obra como a de Simmonds lança uma nova luz sobre possíveis leituras para o poema de Dickinson. Como T. S. Eliot argumenta em "Tradition and The Individual Talent", enquanto obras de arte do presente são influenciadas pelas do passado, elas também afetam a ordem existente de elementos. Isto é, a tradição é reconhecida não apenas como legado, mas como troca fluida, recíproca e aberta que resulta numa espécie de contemporaneidade entre escritores. A questão que se apresenta nesse diálogo é mediada, ainda, pela oralidade do rádio, borrando os limiares que diferenciam gêneros literários. A prosa de Simmonds é tanto poética quanto é dramática. Sua entrega ao ouvinte toma vida na voz do ator, que conduz e narra o conto em terceira pessoa enquanto incorpora nas falas a voz, as hesitações, enfim, a humanidade do protagonista. Neste ambiente de interartes e intergêneros, a releitura da obra da poeta de Amherst encontra um poderoso canal de expressão, sendo ela própria altamente imagética e carregada de convites para uma leitura não-passiva do leitor, encontrando esse chamado sua expressão máxima no famoso "I’m Nobody! Who are You? / Are you - Nobody - too?". Em sua empreitada, Simmonds oferece uma resposta. 
Com a descrição "um homem tenta ressuscitar seu casamento" como único guia para o que virá a seguir, o ouvinte adentra o universo de Simmonds com curiosidade. 0 sotaque do ator imediatamente nos transporta para o universo escocês do protagonista. No entanto, por trás dos marcadores pontuais, a trama transcorre num ambiente mental e emocional curiosamente inefável. Somos apresentados, primeiramente, não ao homem, mas ao olhar dele sobre o olhar de um artista sobre a sua esposa. Um recorte da ausência que, mais do que a presença, dá o tom do conto. O protagonista sem nome observa representações da esposa e no fluxo de consciência que propele o conto, suas ações se confundem com inseguranças e elucubrações. Ele faz ao retrato perguntas que não ousaria fazer à mulher: “O que há nos olhos dela? (...) Uma espécie de anseio, ou desejo talvez? Ele se aproxima do retrato como se este pudesse falar: 'Angelica,' - ele sussurra; 'Me diga se não é amor.'”. A desconexão e subsequente busca do protagonista por conciliar a imagem da mulher amada no quadro ao indivíduo inatingível é o fio condutor do enredo. Noções de sucesso e fracasso são categorias pelas quais o protagonista circunscreve a vida. Enquanto ele parece sugerir que o distanciamento da mulher estaria relacionado ao fato de ele ter perdido seu restaurante e, desde então, ter parado de cozinhar para ela, sua musa, os breves vislumbres que temos de Angelica parecem sugerir um descompasso de alcance mais amplo do que a ideia de que ela sentia falta de sua posição anterior. Enquanto ele vê o trabalho dela como modelo como uma posição de objeto passivo a ser admirado, ela parece simplesmente sentir a necessidade de lutar pelas asas - e penas - da esperança libertadora do poema de Dickinson.

Embora conte que Angelica ansiava por uma carreira artística, o protagonista interpreta a vontade ou saudade "de ser musa" como uma espécie de crítica à sua própria inércia. No entanto, suas interpretações das ações de Angelica frequentemente entram 
em contradição com reinterpretações surgidas pouco depois com pouca ou nenhuma participação ativa da mulher. Angelica é sempre filtrada pelo olhar volátil de um homem em crise. No final, a busca por ela parece ter pouco a ver com o indivíduo e mais com a mulher que habita no imaginário do protagonista, que se vê como artista e encontra em Walter, o novo companheiro de Angelica, e não na mulher, uma espécie de camaradagem criadora. É através dos quadros dele, afinal, que ele tenta dialogar em sua construção do que seria Angelica: sempre musa, nunca artista, sempre discutida e interpretada e nunca parte da discussão.

Simbolismos e imagens aproximam Simmonds do chamado poético dickinsoniano. Reassumindo sua posição de chef-artista como meio de recuperar seu casamento, o protagonista descreve em detalhes as etapas da preparação de um faisão que ele comprou recém-morto. A partir do processo de preparo da ave para o consumo, o conto parece emular uma espécie de reflexo assimétrico do poema de Dickinson: enquanto a poeta define "Esperança" - entre aspas - como a "coisa com penas / que se empoleira na alma / e canta a melodia sem palavras / e jamais para", o primeiro ato do protagonista é justamente privar a ave morta de suas penas com movimentos "breves e firmes". Os tufos remanescentes serão queimados depois. Ele descreve casualmente como "inclinou e cortou as asas". O desinteresse do personagem em relação ao ato corriqueiro de depenar o faisão é contrabalançado pela atenção que ele dedica à descrição do conteúdo estomacal da ave. Ele reflete com melancolia sobre a sua última refeição, enquanto sente um jorro de emoção ao decapitar a ave e segurar a cabeça em suas mãos. O protagonista é brevemente interrompido por um som no jardim e não sabe precisar se era uma carriça ou um melro-preto. "Angelica saberia", ele observa, pausa e retoma suas atividades na cozinha. O interlúdio evoca as imagens da segunda estrofe do poema que inspirou o 
conto, a partir do qual, decididamente, o eu-lírico dickinsoniano e o protagonista do conto tomam vias diferentes. Enquanto o poema louva a resistência do pequeno pássaro que enfrenta a tempestades e ventanias (e aqui, o emprego do termo Gale, com a primeira letra capitalizada, personificando aquilo que se opõe à Esperança e à liberdade oferecida por ela, é fundamental), Simmonds emprega o mesmo termo na voz do narrador: quando o protagonista tem suas expectativas para o jantar de reencontro frustradas por Angelica - novamente assinalando o descompasso entre os dois - ele decide levar o jantar, o faisão, até ela, seja na sua casa, seja no seu local de trabalho. Ele descreve: “Um vendaval (gale) sopra na noite miserável enquanto ele entra no carro e põe a caixa cuidadosamente no chão do lado do passageiro". A esperança dele resiste, mas o seu recorte da realidade é mal concebido.

Ao preparar o faisão para consumo, pouca atenção é dispensada ao corte simbólico das asas, desatenção que reflete aquela descrita no início do conto, quando ele diz não ter levado a sério as inclinações artísticas de Angelica. A imagem do pássaro em busca de liberdade permeia a obra de Emily Dickinson. Pássaros são focos da atenção de Angelica. O protagonista equivoca-se ao forjar uma esperança condicionada e não livre, projetada na figura da mulher: Angelica personifica a esperança do protagonista como símbolo de dias áureos e assim fica claro que ele sempre vai procurá-la no lugar errado. Ela é intangível não por ser musa, mas por ser sujeito. A cena final, onde o protagonista finalmente encontra Angelica na universidade posando para estudantes de pintura, ele retoma seu devaneio e cria resoluções nas quais Angelica não tem voz. No entanto, o último ato- o primeiro ato de fato - de Angelica, ecoa o verso final de Dickinson. Ao se perder em lembranças da primeira vez que a viu, não do seu primeiro encontro, ele decide que precisa falar com ela. O fim da aula, contudo, traz uma ruptura do quadro 
romantizado. A mulher atravessa a tela: "Ela puxa um roupão, o amarra, vira e o apanha ali, através do vidro. Ele é pego de surpresa, então se sobressalta um pouco." Como a coisa com penas de Dickinson, Angelica não pede nada aos homens que pedem tanto dela. Frustrado com o cancelamento do encontro, ele havia lamentado: "Ele só sabe que precisa dela. E precisam dela em outro lugar". Do que Angelica precisa? O que ela vem a ser jamais será acessível ao homem que não reconhece o canto do pássaro que lamenta o equívoco de privar alguém de suas asas em prol da própria satisfação. O eu-lírico de Dickinson encerra o poema contando que mesmo em meio às piores intempéries, it, a esperança que se empoleira na alma e canta sem parar, jamais pediu uma migalha dele. $\mathrm{O}$ protagonista percorre um caminho sinuoso, mas jamais vai encontrar o que procura, pois somente o enxerga em relação a si. Com a nota positiva que encerra o conto, onde o dia longo e confuso começa a cantar, Angelica se faz sujeito da própria sentença e canta a melodia dickinsoniana, trazendo mérito a Simmonds como leitora e momentum como escritora.

\section{Referência}

GORDON, Lyndall. Lives like loaded guns: Emily Dickinson and her family's feuds. Nova York: Penguin, 2010.

Recebido em 9 de março de 2018.

Aceito em 16 de maio de 2018. 